\title{
Peter A. Hargous y la TRC en 1852 o de cómo tratar de recuperar una concesión y fracasar en el intento
}

\author{
Ana Rosa Suárez Argüello \\ INSTITUTO MORA
}

\begin{abstract}
El artículo presenta a la Tehuantepec Railroad Company, empresa estadunidense que quiso construir una vía de comunicación interoceánica en el istmo de Tehuantepec; refiere cómo sus propietarios lucharon por conservar la concesión que el Congreso de México había anulado, y revisa los recursos que se emplearon para hacer ruido, obtener el apoyo del Senado y obligar a la administración de Millard Fillmore a intervenir en su favor.
\end{abstract}

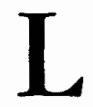

a diplomacia mexicana es astuta, fértil en inventiva y sus recursos carecen de escrúpulos [...]". ${ }^{1}$ Estas palabras, escritas por Peter A. Hargous a mediados de 1852, ilustran el sentir de un comerciante estadunidense, quien acababa de perder una batalla en la guerra que libraba contra el

\footnotetext{
1 Peter A. Hargous a Daniel Webster, Washington, 11 de mayo de 1852 en The National Archives of Washington, Records of the De. partment of State, Record Group 59 (en adelante NAW), Miscellaneous Letters of the Department of State, 1789-1906 (en adelante Miscellaneous Letters), mf. M179, rollo 131.
}

gobierno de México para hacer efectiva la concesión de Tehuantepec.

Llaman también la atención sobre un camino poco recorrido en la historia diplomática nacional, el de los actores no estatales, que permite abordar temas diversos de los usuales y arribar a explicaciones nuevas, distintas de las sabidas y más aclaratorias de la realidad actual. Y es que en el estudio de las relaciones México-Estados Unidos estos actores, y muy en particular lo que hoy llamamos iniciativa o sector privado, han sido rara vez el sujeto o el objetivo central, pese a que en muchas ocasiones desempeñaron un papel pri- 
mordial en los asuntos externos de ambos países.

Lo anterior, que se puede aplicar en mayor o menor grado en ambas historiografías, es más cierto cuando se repasa lo publicado sobre los primeros 50 años del trato bilateral. Salvo algunos autores, que en sus análisis reconocen el espacio de los hombres de negocios, la gran mayoría se ha orientado a revisar el intercambio entre cancillerías y legaciones. ${ }^{2} \mathrm{Y}$ en realidad esta ausencia resulta asombrosa a la vez que desafortunada, en tanto que impide la comprensión cabal de un proceso. Si se considera que la expansión de Estados Unidos a costa de México fue, durante este lapso, un factor decisivo en la historia de los dos países, y que dicha expansión no se puede entender sin la actuación de esos estadunidenses deseosos de adquirir privilegios de tierra y colonización, de asegurarse el monopolio de otros bienes, de aumentar sus capitales en economías tan débiles como la mexicana y, por último, de obtener la fama y la gratitud de sus compatriotas mediante la anexión de territorios, es casi imposible explicar por qué ha sido desdeñada la presencia de los negocios en la política exterior y la diplomacia. ${ }^{3}$

\footnotetext{
${ }^{2}$ Para la historiografia estadunidense sería el caso de las obras de Pletcher, Diplomacy, 1975; Garber, Gadsden, 1934; Donathon C. Olliff, Reforma, 1981; Rippy, "Diplomacy" 1920, pp. 503 531 , y Schoonover, 1978. Para la historiografia mexicana vale mencionar a Gurza, Gestión, 1997 y varios de los trabajos de Suárez y Te. rrazas (comps.), Política, 1997.

${ }^{3}$ Nelson, "Destiny", pp. 56-57. En el caso de la historiografía estadunidense, esto sucedió a pesar del influjo de la Nueva Izquierda, que a
}

Money talks, dicen los vecinos del norte, el dinero habla. Y esto puede ser cierto. La pretensión de proporcionar a las empresas y los empresarios el peso que merecen dentro del estudio de la política exterior de México y Estados Unidos, y las evidencias reunidas hasta hoy, permiten afirmar que en todas y cada una de las fricciones que hubo durante el decenio de 1850 por la cuestión de Tehuantepec, la ambición de obtener ganancias por parte de quienes peleaban por la concesión ístmica permeó la relación bilateral.

Es propósito de este artículo presentar uno de los negocios que se involucraron en la construcción de la obra interoceánica, la Tehuantepec Railroad Company, referirlo a una etapa de crisis en su existencia, y elucidar los recursos que empleó para hacer ruido y de tal modo recuperar el favor del gobierno en Washington. Como se anuncia en el título, el intento empresarial fracasó, pero indudablemente sí se afectó la relación bilateral.

Money talks. Sigamos entonces la pista del dinero, y comencemos.

\section{EL NEGOCIO: LA TEHUANTEPEC RAILROAD COMPANY}

La Tehuantepec Railroad Company (en adelante TRC) propuso, a mediados del siglo XIX, la construcción de una comunicación interoceánica en el istmo de

partir de los años sesenta defendió el peso de los intereses económicos en la política exterior e influyó en algunos trabajos, aunque para otros periodos. 


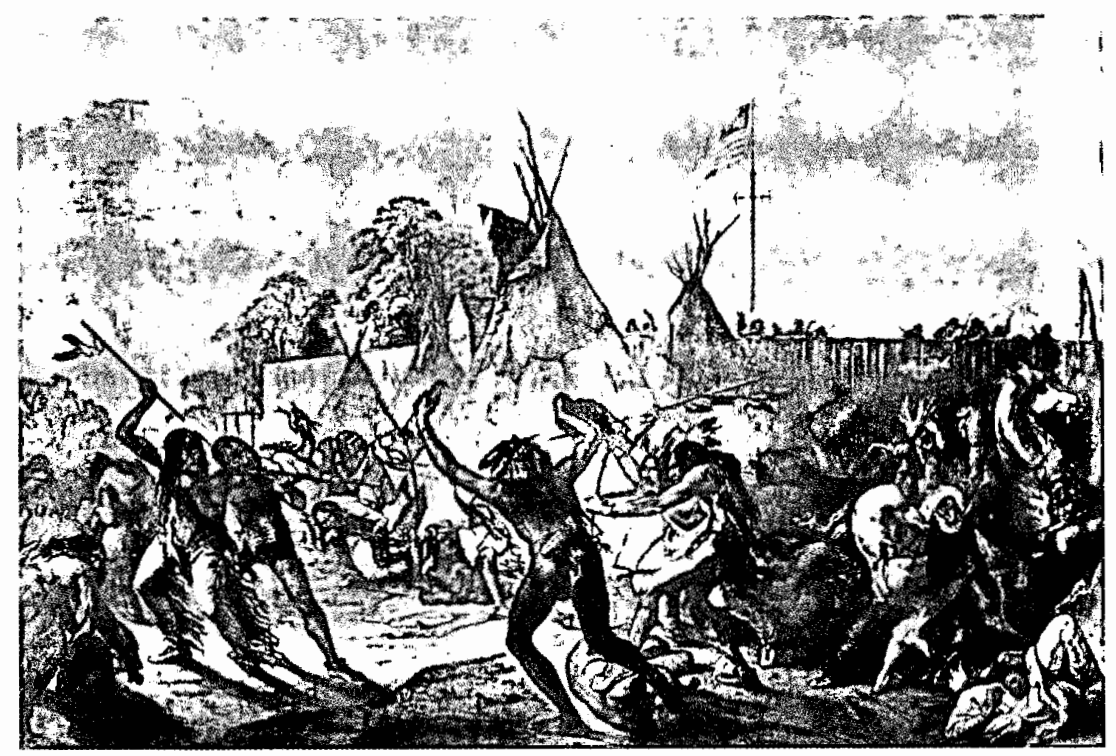

Tehuantepec. Operaba con base en una concesión otorgada por Antonio López de Santa Anna a José de Garay en 1842, la cual había cambiado varias veces de manos y se hallaba entonces en las de Peter A. Hargous. Éste aparentaba ser su único dueño y administrador, a través de una serie de convenios privados y desconocidos con De Garay, y entre éste y otros personajes como Manuel Escandón, Mariano Gálvez y Gabriel Valencia, los primeros suscritos para "americanizar" el contrato y ganar así el auxilio de Washington. ¿Quién era este Peter A. Hargous?, ¿por qué tuvo tanta influencia en la cuestión de Tehuantepec? Se trataba del socio principal de la firma Hargous Brothers de Nueva York, la cual soste- nía tratos comerciales y financieros con México, entre otros lugares del mundo. Sus oficinas en Estados Unidos servían como sede para sus distintos movimientos, en tanto que una lí. nea de barcos de su propiedad recorría con regularidad la ruta Nueva York-La Habana-Veracruz y transportaba todo tipo de mercancías.

Hargous era un miembro sobresaliente de la sociedad neoyorquina, no sólo como hombre de negocios, sino por sus nexos políticos, pues tenía abiertas las puertas en las instancias oficiales de Washington. Estaba asociado con su hermano Louis Eugène, quien había sido comerciante y vicecónsul en Veracruz por varios años y tenía fuertes lazos, mediante matrimonio y com- 
padrazgos, con la familia Trigueros, a su vez vinculada con el entonces llamado grupo santannista; el menor de los hermanos era Louis Stanislaus, avecindado en Veracruz de 1833 a 1847 , y desde 1848 en la ciudad de México, donde se hallaba la sede de L. S. Hargous and Company, negocio dedicado a las exportaciones e importaciones y con inversiones bancarias y en bienes muebles, inmuebles y obras públicas. Ambas empresas Hargous se complementaban: la una cuidaba los asuntos de la otra, atendía sus problemas locales, le procuraba información confiable y otorgaba crédito. Las dos disponían de los medios para actuar como palanca poderosa, capaz de impulsar la empresa de Tehuantepec.

Estados Unidos se había mostrado atraído por la idea de construir una comunicación entre el Atlántico y el Pacífico desde la década de 1820, cuando tanto el gobierno como algunos particulares abrieron los ojos a las posibilidades que ofrecían Nicaragua y Panamá. Un impulso importante fue el deseo de incrementar el comercio con Asia, que se veía obligado a utilizar la muy larga y peligrosa ruta por el cabo de Hornos.

El reparto del territorio de Oregón, que dio al país un carácter transcontinental desde 1846, y la guerra contra México, con la derivada ocupación de California y la fiebre del oro iniciada a principios de 1848, aumentaron el interés. Tanto el gobierno como particulares se pusieron en acción y respectivamente buscaron acuerdos con Nueva Granada, Nicaragua y México y se otorgaron contratos para facilitar la vinculación entre los dos litorales. La com- petencia se hizo muy reñida: mientras la American Atlantic and Pacific Ship Canal Company de Cornelius Vanderbilt trabajaba en el paso nicaragüense, la Pacific Mail Steamship Company, que presidía William Henry Aspinwall, lo hacía en el istmo de Panamá.

Para los hermanos Hargous, la ruta por México daría lugar a "una completa revolución en la comunidad comercial y un aumento de la riqueza en cada parte del mundo". " Peter era el más comprometido, y se convirtió en líder del proyecto desde el 5 de febrero de 1849 , día en que recibió la concesión de De Garay mediante un traspaso legal. ${ }^{5}$ Hizo cuanto pudo para llegar a la cima: cabildeó en el Capitolio y en la prensa y logró el respaldo de la Casa Blanca, el Departamento de Estado (sobre todo de Daniel Webster) y la legación en México. Fue Robert P. Letcher, a la sazón ministro en esta ciu. dad, quien negoció un tratado que le era muy propicio, pues el gobierno mexicano lo reconocía tácitamente como tenedor del privilegio y se accedía a que ambos países pudieran proteger la obra ístmica, aun con fuerzas de mar $y$ tierra.

P. A. Hargous se ocupó también de recaudar fondos. En esto tuvo problemas, ya que no consiguió inversionistas en Nueva York ni tampoco un subsidio en Washington para transportar

\footnotetext{
${ }^{4}$ Hargous Brothers a Manning y Mackintosh, Nueva York, 15 de septiembre de 1849 en Benson Latin American Collection, General Libraries, University of Texas at Austin, (en adelante BLAC-UTA), Manning and Mackintosh Papers, 1714-1894, rollo 157, folder 93.

${ }^{5}$ Escritura de traspaso, Nueva York, 5 de febrero de 1849 en "Message", 1852, p. 167.
} 
el correo. Sin embargo, a fines de 1849 recibió la oferta de algunos habitantes de Nueva Orleans, ${ }^{6}$ ciudad muy deseosa de atraer el comercio de la cuenca del Pacífico hacia el Golfo de México, y de allí, donde ella quería reinar, redistribuirlo en ambas márgenes del Atlántico.

Los tratos culminaron el 2 de mayo de 1850 , cuando varios ciudadanos de Nueva Orleans convinieron en formar una compañía que tomara sobre sí el proyecto de Tehuantepec y en concertar los préstamos que fuesen precisos. Hargous les transfirió la concesión por un lapso de dos años y adelantó 500000 dólares para las exploraciones, la apertura de caminos y los salarios de los ingenieros, asegurándose un tercio de las acciones y los dividendos al igual que su parte en las tareas de organización y administración. ${ }^{7}$

Siendo así la TRC se constituyó a fines de noviembre, con Judah P. Benjamin como presidente y Bernard Fallon como secretario. ${ }^{8}$ Las operaciones se iniciaron de inmediato: se abrió una

\footnotetext{
${ }^{6}$ Hargous Brothers a Manning y Mackintosh, Nueva York, 22 de noviembre de 1849 en BlıCUTA, Manning and Mackintosb Papers, rollo 157 , folder 93 .

7 "Areement between the Permanent Committee appointed by the citizens of New Orleans, to devise means for establishing a communication across the isthmus of Tehuantepec, and Mr. Peter A. Hargous, of New York, as holder of the grant relative to that isthmus, made by the government of Mexico to Mr. José de Garay", [Nueva Orleans, 18 de abril de 1851] en "Message", 1852, p. 176.

${ }^{8}$ Hargous Brothers a Manning y Mackintosh, Nueva York, 15 de septiembre de 1849 en BIACUTA, Manning an Mackintosh Papers, 1714 1894, rollo 157 , folder 93 .
}

oficina en Nueva Orleans para vender acciones y promover la empresa en los periódicos; se despacharon dos partidas de exploración, que probaron la viabilidad de la ruta tehuana y reconocieron la bahía de Ventosa como posible terminal en la ribera del Pacífico; se abrieron veredas; se habilitaron puertos para recibir abastecimientos; se contrataron jornaleros y se compraron herramientas y materiales de construcción. La compañía llegó más lejos, pues, para reunir dinero e iniciar el envío de colonos, comenzó a vender tierras en el istmo.

Sin embargo, el temor a que la obra interoceánica quedara en manos de ciudadanos estadunidenses y éstos repitiesen la experiencia de Texas en el sur del país alarmó a los políticos y a la opinión pública en México. Las acciones de la TRC y la suspicacia hacia Estados Unidos pesaron más que las posibles ventajas. El régimen de Mariano Arista, que tomó el poder desde el $\mathbf{1 . 5}$ de enero de 1851, le declaró la guerra: una vez que el Congreso anuló la concesión de De Garay, ordenó la expulsión de los ingenieros y jornaleros de la empresa, el decomiso de sus bienes, la suspensión del comercio de altura en los puertos locales, el cierre de los consulados estadunidenses y la militarización de la zona.

Con todo, los participantes en el proyecto no desistieron. Confiaban en el influjo de Washington: México no osaría oponerse a un acuerdo que había merecido la aprobación del Senado y la ratificación del presidente de Estados Unidos. En este contexto, la noticia del rechazo del Tratado de Tehuantepec por la Cámara de Diputados, el 6 
de abril de 1852, los sacudió. Así lo manifestó Peter A. Hargous, quien el 18 de mayo declaró que el Congreso mexicano había actuado en forma arbitraria e injustificable y conminó a su gobierno a someter el caso al poder legislativo, de modo que éste lo autorizara a amparar debidamente los derechos de sus conciudadanos. ${ }^{9}$

No fue así. Pese a la desilusión sufrida, el presidente Millard Fillmore no deseaba complicar su último año en Washington e involucrar a su administración en una guerra con México. ${ }^{10} \mathrm{El}$ secretario de Estado Webster lo secundó. A juicio de ambos, se había hecho todo lo que se debía y podía por los empresarios: éstos tendrían que resignarse con una indemnización. ${ }^{11}$

¿Cuál fue la reacción de Peter A. Hargous ante esta catástrofe?, ¿qué hicieron sus socios en Nueva Orleans y México? Por lo pronto, y para cubrirse, el neoyorquino remitió al Departamento de Estado una relación de los daños, y la reclamación de 5283000 pesos. $^{12}$

\footnotetext{
${ }^{9}$ P. A. Hargous a Daniel Webster, Washington, 18 de mayo de 1852 en NAw, Miscellaneous Letters, loc. cit., mf. M179, rollo 131.

${ }^{10}$ Como whig, Fillmore se oponía a una intervención armada en el país del sur. Por otro lado, habia resultado perdedor en las elecciones primarias de su partido: el candidato presidencial era el general Winfield Scott, quien se enfrentaba al demócrata y también general Franklin Pierce. Suárez, "iExpansión?", pp. 127-176.

${ }^{11}$ Millard Fillmore a Daniel Webster, Washington, 19 de julio de 1851 en Library of Congress, Daniel Webster Papers, rollo 6 y Daniel Webster a Millard Fillmore [Marshfield, Massachusetts], 21 de julio de 1851 en Shewmaker y Stevens, Papers, 1986, vol. 8, p. 512.

${ }^{12}$ P. A. Hargous a Daniel Webster, Washington, 5 de junio de 1852 en "Message", 1852, p. 150 .
}

Se trataba de una suma cuantiosa, exagerada por dos motivos probables: uno especulativo, que pretendía convertir en casi 6000000 los 500000 dólares invertidos. El otro era propiciar un conflicto, pues sin duda los mexicanos se negarían a pagar y, como tantas veces en el pasado, Estados Unidos se vería forzado a intervenir. En ambos casos, los quejosos resultarían beneficiados.

Las historias diplomáticas más conocidas se detienen aquí. Aunque Hargous y los suyos continúan en algunas, sus apariciones (durante el largo proceso que culminó en el Tratado de La Mesilla y cuando se formó la Louisiana Tehuantepec Company, a la que los presidentes Ignacio Comonfort y Benito Juárez otorgaron el contrato para la vía interoceánica) ocupan pocos párrafos. Sin embargo, el estudio de sus movimientos posteriores ha probado que no dejaron de actuar, y que esto les permitió mantener su presencia en el escenario México-Estados Unidos. Ahora bien, más que hacer efectiva la reclamación, lo que querían era que la administración en Washington les devolviera su ayuda y obligase a los vecinos a reconocer sus derechos y aceptar sus operaciones. Esto, sin duda, sería mejor que cualquier pago.

\section{La BaTALLA POR la CONCESIón}

Al cerrárseles el acceso a la Casa Blanca y el Departamento de Estado, Hargous y compañía tuvieron que valerse de otros medios para alcanzar sus fines.

Lo primero fue apelar a la opinión pública mediante la circulación de fo- 
lletos suscritos por ellos mismos, ${ }^{13}$ y la ayuda de la prensa. Periódicos y revistas de varios lugares, pero sobre todo de Nueva York y Nueva Orleans, donde gozaban de mayor ascendiente, acusaron al gobierno mexicano de gran variedad de crímenes, entre otros de rechazar un tratado útil para toda la humanidad, de violar algo tan sagrado como era un contrato y de discriminar a los estadunidenses por su origen nacional. Se reiteró el influjo siniestro de Gran Bretaña y aun se exigió que Washington comprara el istmo o lo tomase por la fuerza. ${ }^{14}$

Hargous se sacó de la manga una carta importante. Persuadió a su amigo, James M. Mason, senador por Virginia, para que dejara oír su voz sobre el tema interoceánico. ${ }^{15} \mathrm{Se}$ desconoce, en realidad, cuán cercanos eran sus nexos, pero el hecho de que para el senador la mejor ruta fuera la mexicana y se hubiese cometido una arbitrariedad con los concesionarios dio esperanzas a estos últimos durante los meses siguientes.

A solicitud de Mason, el Senado pidió al ejecutivo que remitiera la corres-

${ }^{13}$ Hargous y New Orleans Company, Remonstrance, 1852, pp. 33-34; A review of the Tebuantepec controversy, Georgetown, D. C. [s. 1.], 1853 en Rippy, "Diplomacy", 1920, p. 522; The Picayune, 8 de agosto de 1852.

${ }^{14}$ Véase ejemplos en The Picayune, 15 de mayo y 12 de noviembre de 1852; De Bow's, 1853, vol. 14, pp. 1-2, 19, passim; Times, Nueva York, 5 y 24 de mayo de 1852.

${ }^{15}$ Francisco de Paula Arrangoiz a Mariano Yáñez, Nueva York, 25 de octubre y 2 de noviembre de 1852 en Archivo Histórico de la Secretaría de Relaciones Exteriores de México (en adelante AHSREM), exp. L-E-1511, fs. 169, 180-181. pondencia y tratados relativos a la cuestión de Tehuantepec el 19 de julio de $1852 .{ }^{16}$ Fillmore contestó el 27 y su mensaje, junto con los documentos anexos, se refirió al Comité de Relaciones Exteriores. ${ }^{17}$ Éste se tomó algún tiempo para deliberar. Mason, quien lo presidía, se reunió con Webster y con Manuel Larrainzar, el ministro de México en Washington, para reunir más información. El grupo Hargous-Nueva Orleans mantuvo la presión, pidiendo la intervención del Senado para que les devolviesen sus bienes o los compensaran por los daños sufridos y advirtiendo que, de elegirse lo segundo, la obra tehuana jamás se convertiría en una realidad. ${ }^{18}$

Por fin, el comité hizo tres recomendaciones al pleno el 30 de agosto: 1) que el gobierno suspendiera negociaciones que eran incompatibles con su "dignidad"; 2) que sólo aceptase las propuestas mexicanas acordes con sus demandas, y 3) que tomara las medidas necesarias para proteger los derechos de sus ciudadanos en el exterior. ${ }^{19}$

Ahora bien, como la sesión termina. ba al día siguiente, la votación se postergó hasta diciembre, para cuando la labor legislativa se reanudara. Antes de retirarse, sin embargo, Walter Brooke,

${ }^{16}$ The Congressional Globe, Washington, 19 de julio de 1852, mf. 11, rollo 26, p. 1833 .

${ }_{17}$ Millard Fillmore al Senado, Washington, 27 de julio de 1852 en "Message", 1852, p. 1.

${ }^{18}$ Citado en "The Tehuantepec Treaty. Memorial of the American Tehuantepec Company", Times, Nueva York, 10 de agosto de 1852.

19 "Report", 1852, pp. 1-6 y The Congressional Globe, Washington, 31 de agosto de 1852 , mf. 11, rollo 26 , p. 2465 . 
el senador por Mississippi, hizo una proposición más agresiva, la cual también quedó asentada para su futura discusión: dar un plazo a los mexicanos, esto es, si los tenedores del privilegio de De Garay no recuperaban la posesión de sus propiedades y derechos antes del 1 de marzo de 1853, Estados Unidos actuaría en consecuencia. ${ }^{20}$ A los empresarios no les quedó más que aguardar, y afanarse en el frente mexicano.

En el país del sur, Hargous y socios tenían poco margen de acción. La oposición oficial y pública a sus planes era total y faltaba quien los ayudara en la legación estadunidense. El trato se redujo a su mínima expresión, Letcher regresó después a su país y su sucesor, Alfred Conkling, quien llegó en noviembre, se negó a cooperar con ellos. ${ }^{21}$ Alguna ayuda brindó Mariano Gálvez, uno de los socios, pero el folleto que publicó sólo hizo ruido, nada más. ${ }^{22}$ Los recursos que se aplicaran tenían,

\footnotetext{
20 "Resolution", 1852 y The Congressional Globe, Washington, 32 Congreso, 1 sesión, 31 de agosto de 1852, mf. 11, rollo 26 , p. 2465 .

${ }^{21}$ Un encargado de negocios quedó al frente de los asuntos de Estados Unidos por más de tres meses, pero debió estar limitado en su actuación por su carácter interino.

${ }^{22}$ Gálvez, Mariano, 1853, passim. Gálvez debió tener por algún tiempo ła ayuda de Louis S. Hargous como apoderado que era de su hermano y de los ciudadanos de Nueva Orleans vinculados con el proyecto de Tehuantepec. Poder de Peter Conrey, hijo, y Bernard Fallon a Louis S. Hargous, Nueva Orleans, 23 de noviembre de 1850 en AHSREM, exp. L-E-1510, fs. 198-200. Sin embargo, L. S. Hargous salió a poco de la república mexicana, llamado por un comité del Senado. Testimonio de Louis S. Hargous, Washington, 19 de enero de 1853 en "Re. port", 1854, mf. 708 , vol. 2, pp. 99-100.
}

por tanto, que ser distintos. Hargous decidió entonces aprovechar la convo. catoria lanzada por el gobierno de Arista para formar una compañía mexicana o mixta que se encargara de la obra de Tehuantepec, y pidió a Alexander Bellangé, un empresario francés radicado en México, que actuase como su testaferro. ${ }^{23}$ Hubiera podido participar abiertamente, y a las autoridades mexicanas les hubiera gustado, pero hacerlo equivalía a admitir la ilegitimidad del contrato de De Garay y renunciar a la posible protección de Washington.

Bellangé accedió y presentó una postura en nombre de la llamada Compañía Nacional, la cual -dijo- operaría desde Oaxaca, Veracruz, Chiapas, México o el Distrito Federal, y estaba formada por propietarios originarios de dichos lugares, quienes se identificarían en cuanto se firmara el contrato. ${ }^{24} \mathrm{La}$ operación corrió al principio con suerte, pues la apoyaron Mariano Yáñez, el secretario de Relaciones, y la comisión de diputados asignada. Esta última rindió incluso un dictamen positivo, lo cual indignó a los otros competidores, quienes se valieron de la prensa para denunciar como agente de la TRC a Bellangé, ${ }^{25}$ al punto que éste, quien aún se negaba a dar los nombres de sus socios, respondió con cinismo que en su compañía sólo había mexicanos y ni Hargous ni De Garay, "que han he-

${ }^{23}$ Elegir a un estadunidense como agente hubiera despertado, sin duda, una gran suspicacia.

24 "Proposiciones del señor Bellangé" [México, agosto de 1852] en Documentos, 1852 , p. 38 .

${ }^{25}$ Dictamen, 1852, pp: 3-5, 12; "Tehuantepec", El Universal, 19 de noviembre de 1852. 
cho mucho mal a la república", formaban parte de ella. ${ }^{26}$ Es más, cuando se le acusó de carecer de fondos, presentó el certificado de un casa de comercio, donde constaba que tenía depositados 300000 pesos en efectivo y se mostró además bien dispuesto a asociarse con otros. ${ }^{27}$

Por su parte, él (y quienes estaban tras de él), cabildeaban en los diarios, sin gran éxito, ${ }^{28}$ y entre los diputados. Circuló aun el rumor de que ofrecían acciones a cambio de votos. Así se entendía que la comisión legislativa facultada para revisar las posturas se hubiera "equivocado" en su beneficio. Aunque los congresistas lo negaron enfáticamente, ${ }^{29}$ el hecho es que el soborno era una práctica común y existen indicios suficientes de que se utilizó entonces. $^{30}$

\footnotetext{
${ }^{26}$ Citado en "Tehuantepec", El Universal, 21 de noviembre de 1852.

27 "Tehuantepec" y "Una palabra más sobre
} Tehuantepec", El Monitor, 1 (suplemento) y 3 de diciembre de 1852. Más tarde, El Siglo $X I X$ aseguró que los 300000 pesos de Bellangé no eran dinero, sino créditos contra el gobierno. "Cuestión de Tehuantepec", El Siglo XIX, 30 de noviembre de 1852 , México.

28 "Negocio de Tehuantepec", El Universal, 2 de julio de 1852; Ramírez, Memorias, 1853, pp. $666,668$.

${ }^{29}$ Alfred Conkling a Edward Everett, México, 23 de noviembre de 1852 en NAW, Despatches from the United States ministers to Mexico 1823-1906 (en adelante Despatches), mf. M97, rollo 17 , doc. núm. 1 ; "Cuestión de Tehuantepec" y "El ministro de Relaciones y el negocio de Tehuantepec", El Siglo $X I X, 27$ y 28 de noviembre y 14 de diciembre de 1852; "Istmo de Tehuantepec", El Universal, 29 de noviembre de 1852 .

${ }^{30}$ Percy W. Doyle a su gobierno, México, 3 de diciembre de 1852 en Public Record Oficce of London, Foreign Office Papers, $\mathrm{mf}$ (en ade-
Sin duda, la mejor ayuda que recibió Bellangé fue la de Mariano Yáñez, quien, aunque había pasado el asunto al Congreso, no dejaba de entrometerse, y que ante el reiterado reproche de que Bellangé era agente de Hargous, declaraba que eso carecía de importancia si sus propuestas tenían un carácter realmente mexicano. ${ }^{31}$ De pronto, sin embargo, el ministro pidió a la Cámara que aprobara la oferta de la Compañía de Guanajuato, pues ésta le parecía más segura para la nacionalidad. Así se hizo y el caso se turnó al Senado. ${ }^{32}$ ¿Qué había sucedido? La versión oficial fue que, al "saber de la manera más positiva" que los directores y socios ocultos de la compañía de Bellangé eran los interesados en la concesión De Garay, no hubo más que actuar en consecuencia. ${ }^{33}$ Sin embargo, como ya se vio,

lante $\mathrm{FO} / 50$ ), rollo 107 , vol. 253, f. 370 ; Alfred Conkling a Edward Everett, México, 23 de noviembre de 1852 en Naw, Despatcbes, loc. cit., mf. M97, rollo 17, doc. núm. 1; De la Fuente, Discurso, 1852, pp. 6-12; "Una palabra más sobre Tehuantepec", El Monitor, México, 5 de diciembre de 1852.

31 "Tehuantepec" en El Monitor, México, 1 de diciembre de 1852, suplemento; "Istmo de Tehuantepec" y "Tehuantepec", El Universal, México, 26 y 30 de noviembre y 12 de diciembre de 1852 .

32 "Dictamen de la mayoría de las comisiones de Industria y primera de Hacienda unidas en la Cámara de Diputados, sobre la iniciativa del gobierno, contraída a la aprobación de las condiciones presentadas por la Companía de Guanajuato, para la apertura de una vía de comunicación interoceánica por el istmo de Tebuantepec, y voto particular del señor Enciso", El Monitor, 7 y 8 de diciembre de 1852.

${ }^{33}$ Mariano Yáñez a Manuel Larrainzar, México, 1 de diciembre de 1852 en AHSREM, Archivo de la Embajada de México en los Estados Unidos de América, leg. 37, exp. 2. 
Yáñez conocía esta imputación y le había restado valor. ${ }^{34} \mathrm{El}$ asunto es, a la fecha, un enigma dificil de resolver.

De cualquier modo, el grupo Hargous-Nueva Orleans había quedado fuera del frente mexicano, aunque sus integrantes no cejaron en la lucha, haciendo llegar a los diarios artículos publicados en la prensa estadunidense en los que sobraban amenazas y faltaban intentos de conciliación, al igual que cartas presuntamente enviadas desde Washington, donde se afirmaba que el poder legislativo de Estados Unidos respaldaría a la empresa. ${ }^{35}$ En efecto, faltaba que el Senado votara las recomendaciones de su Comité de Relaciones Exteriores; todavía era factible que Mason y sus aliados pudieran prevalecer.

\section{LA REACCIÓN DE LARRAINZAR}

En esta guerra librada por los partidarios de la concesión De Garay, Manuel Larrainzar fue quien defendió el frente diplomático mexicano, ya que, como se indicó arriba, el trato entre la Secretaría de Relaciones y la legación de Estados Unidos se redujo a lo indispensable. Él

${ }^{34}$ Según José María Tornel, Yáñez se vio engañado porque la Compañía de Bellangé estaba "cautelosamente cubierta, escuchada y abrigada con la nacionalidad absoluta, y con los adornos $y$ arreos que tanto placen al verdadero patriotismo". Tornel, Voto, 1852, p. 19.

${ }^{35}$ Percy W. Doyle a su gobierno, México, 3 de diciembre de 1852 en $\mathrm{FO} / 50$, rollo 107 , vol. 253, fs. 370-374; Alfred Conkling a Edward Everett, México, 23 de noviembre de 1852 en NAw, Despatches, loc. cit., mf. M97, r. 17, doc. núm. 1; "Correspondencia particular del Universal", El Universal, México, 8 de noviembre de 1852. se encargó de reiterar al Departamento de Estado el rechazo de México a la concesión De Garay y el Tratado de Tehuantepec, pero hizo notar que su gobierno era tan consciente de la trascendencia de la obra interoceánica que había convocado a su construcción, aunque eso sí, bajo sus condiciones, esto es, sin sacrificar la independencia y la soberanía territoriales ${ }^{36}$ Además, tachó a Hargous y socios de calumniar al país y sus autoridades y de no acogerse a los tribunales nacionales, sino al poderío de Estados Unidos. ${ }^{37}$

Don Manuel se ocupó de combatir a la prensa hostil. Pidió a los cónsules que se valieran de cualquier espacio facilitado por los periódicos amigos y el erario mexicano le giró fondos para pagar la inserción de artículos y documentos traducidos al inglés. ${ }^{38}$ Él mismo refutó a Americus, pluma al servicio de los Hargous que atacaba desde el Washington Republic, ${ }^{39}$ para lo cual adoptó el seudónimo de Veridicus, con el que firmó artículos aparecidos en el New York Herald. ${ }^{40}$ Propició la

\footnotetext{
${ }^{36}$ Manuel Larrainzar a Daniel Webster, México, 31 de mayo de 1852 en NAW, Notes from the Mexican Legation in the United States to the Department of State 1821-1906, mf. M54, rollo 3 .

${ }^{37}$ Manuel Larrainzar a Daniel Webster, México, 10 de julio de 1852 en ibid., rollo 3 .

${ }^{38}$ Larrainzar, Via, 1877 , p. 23.

${ }^{39}$ Americus, "The Tehuantepec negotiations" [The Republic, Washington, 28 de julio de 1852] en AHSREM, exp. L-E-1603, fs. 3-7; Americus, "Comunicado. Negociación de Tehuantepec" [The Republic, Washington, 6 de agosto de 1852] en ibid., exp. L-E-1606, fs. 18-33.

${ }^{40}$ Veridicus, "Tehuantepec", Washington, 28 de julio, 8 y 12 de agosto de 1852 en Larrainzar, Cuestión, 1852, pp. 23-71.
} 
difusión de folletos, uno escrito por José Fernando Ramírez, dos más por él mismo. Uno de estos últimos se publicó en inglés, a tiempo para que los senadores pudieran consultarlo antes de aprobar iniciativa alguna. ${ }^{41}$

Además de la ayuda discreta suministrada por algunos políticos, como Pierre Soulé, senador por Luisiana, ${ }^{42}$ se recibió la ayuda abierta de Thomas H. Benton, ex senador y diputado por Missouri, y Ben E. Green, miembro del cuerpo diplomático, quienes divulgaron sus opiniones en la prensa. Si bien ambos tenian sus propios intereses y defendían la propuesta de que fuera un ferrocarril transcontinental el que comunicase los litorales nacionales, sin duda hicieron valer su influencia en favor de México. ${ }^{43}$

\footnotetext{
${ }^{41}$ Ibid., pp. 3-7. Ramírez, Memoria, 1852; [Larrainzar], Análisis, 1852, pp. 4, 7. En inglés, el texto recibió el título de $A$ review of the report of the committee of foreign affairs of the Senate of the United States relative to the Tebuantepec matters [s. p. i.] y debió de estar disponible a fines de enero de 1853 , antes de que el tema fuera debatido otra vez en el Senado. Manuel Larrainzar a Francisco Facio, Nueva York, 4 de febrero de 1853 en AHSREM, exp. L-E1511 , fs. 146-147, 250-251.

42 Mariano Yáñez a Manuel Larrainzar, México, 8 de noviembre de 1852 en AHSREM, exp. L-E-1511, f. 200. Véase Francisco de Paula Arrangoiz a José Miguel Arroyo, Washington, 7 de enero de 1853 y Nueva York, 3 y 6 de febrero de 1853 en ibid., exp. L-E-1603, fs. 22, 24, 45-46.

43 Thomas H. Benton al pueblo de Missouri, Washington, 21 de septiembre de 1852 , y Benjamin E. Green a James G. Bennett, Dalton, Georgia, 23 de octubre de 1852 en Ramírez, Memorias, 1853 , pp. 876,886 , y Benjamin E. Green a James $G$. Bennett, Washington, 5 de octubre de 1852 en AHSREM, L-E-1511, fs. 127-146.
}

De tal modo, las actividades extra diplomáticas de Hargous y compañía provocaron la reacción de los diplomáticos mexicanos, valerse de las mismas armas que empleaban sus adversarios en la lucha por defender lo que creían ser los mejores intereses de México.

\section{¿LA ÚLTIMA OPORTUNIDAD?}

Las recomendaciones del Comité de Relaciones Exteriores del Senado no se discutieron sino hasta febrero de 1853 , cuando los demócratas Mason y Solomon W. Downs de Luisiana las llevaron de nuevo ante el pleno, reiterando la validez del contrato De Garay y de su traspaso a Peter A. Hargous tanto como el deber del gobierno de hacerlos respetar. Redundaron en la importancia y necesidad de la vía tehuana, a la que dieron un carácter casi "doméstico". Convencidos de que al extenderse a California, Estados Unidos había adquirido el derecho de cruzar por la república contigua, los dos se mostraron bastante aguerridos. Si México no retrocedía, el ejecutivo tendría que "revisar" las relaciones existentes y usar las armas para dominar el tránsito. ${ }^{44}$

Para infortunio de Hargous y demás, dos norteños, William $\mathrm{H}$. Seward de Nueva York y John P. Hale de New Hampshire, salieron al paso de los dos sureños, sin duda con ayuda de los textos difundidos por Larrainzar. Ambos rebatieron las recomendaciones

${ }^{44}$ James M. Mason y Solomon W. Downs al Senado, Washington, 1 y 2 de febrero de 1853 , The Congressional Globe, mf. 11, rollo 27 , apéndice, pp. 137-140. 
que se discutían, pues dudaban de la legalidad del privilegio y de su traspaso, objetaron el auxilio dado a la TRC y manifestaron que la administración que ocuparía la Casa Blanca en unos días no tenía por qué heredar un compromiso militar. ${ }^{45}$ Adujeron que la ruta interoceánica debía atravesar por tierras estadunidenses e insistieron en que las negociaciones y el arbitraje eran el medio para resolver los problemas con México, no la invasión. ${ }^{46}$

El senador Brooke los acusó entonces de guiarse por sentimientos de hostilidad hacia el Sur. Él, como representante de Mississippi, que se beneficiaría si Nueva Orleans se convertía en terminal de la vía tehuana, ratificó su apoyo a la ruta mexicana y recalcó que el recurso bélico podía ser necesario. ${ }^{47}$

De tal forma, la disputa por Tehuantepec se mezcló con las pugnas NorteSur en Estados Unidos. Esto afectó los intereses privados, que el 3 de marzo, cuando la segunda sesión del 32 Congreso dio término, no habían logrado sus fines. Para hacerlo tendrían que apelar al nuevo presidente, a otro gabinete, y proseguir el cabildeo en el Congreso y la prensa. Aunque ciertamente lo hicieron, por lo pronto habían fracasado en su intento.

45 Pierce ganó las elecciones presidenciales de noviembre y tomaría posesión el 4 de marzo.

${ }^{46}$ William $H$. Seward y John $P$. Hale al Senado, Washington, 8 y 15 de febrero de 1853 , The Congressional Globe, $\mathrm{mf} .11$, rollo 27 , apéndice, pp. 140-147, 160-165.

${ }^{47}$ Walter Brooke al Senado, Washington, 16 de febrero de 1853 en ibid., pp. 165-166, 170.

\section{UN PÁRRAFO PARA CONCLUIR}

El seguimiento de las actividades de Peter A. Hargous y sus socios en la TRC durante una etapa difícil en la existencia del negocio, ha permitido establecer la presencia de un grupo de interés privado que se valió de todos los recursos a su alcance, tanto legales como ilegales, para imponer su proyecto. Se trataba de un grupo binacional, con influencia en los altos niveles políticos y administrativos, con capacidad para reunir capitales y difundir su posición. Esto lo dejó incidir en la política exte. rior y la diplomacia de ambos países, no como sus miembros hubieran querido, pues en ese momento los factores internos estadunidenses pesaron más (el regional, sobre todo), pero sí al punto de merecer un espacio mayor en los registros historiográficos.

\section{ARCHIVOS}

AHSREM Archivo Histórico de la Secretaría de Relaciones Exteriores de México.

BLAC-UTA Benson Latin American Collection, General Libraries, University of Texas at Austin.

Library of Congress, Washington.

NAW The National Archives of Washington.

FO Public Record Office of London. Foreign Office Papers.

\section{PERIÓDICOS}

-De Bow's Review of the Soutbern and Western States, Devoted to Commerce, Agriculture, Manufactures, Internal Im- 
provements, Statistics, General Literature, etc., Nueva Orleans.

The Congressional Globe, Washington.

-El Monitor Republicano, ciudad de México.

-New York Daily Times.

-The Picayune, Nueva Orleans.

-El Siglo XIX, ciudad de México.

-El Universal, ciudad de México.

\section{BIBLIOGRAFÍA}

-De la Fuente, Juan Antonio, Discurso pronunciado por el señor Fuente, en la Cámara de Diputados, el día 29 de noviembre de este año, contestando a varias especies publicadas en El Siglo XIX contra las comisiones de industria y primera de bacienda, unidas para examinar el negocio de Tebuantepec: inserto en la acta respectiva, e impresa por acuerdo de la misma cámara, Imprenta de Vicente García Torres, México, 1852.

- Documentos relativos a la apertura de una vía interoceánica por el istmo de Tebuantepec, mandados a imprimir por acuerdo de la Camara de Diputados, Tipografia de Torres, México, 1852.

-Gálvez, Mariano, El Dr. Mariano Gálvez, sobre la cuestión de Tebuantepec, Vicente G. Torres, México, 1853.

-Garber, Paul Neff, The Gadsden Treaty, The University of Pennsylvania, Filadelfia, 1934.

-Gerardo Gurza Lavalle, La gestión diplomática de Jobn Forsyth, 1856-1858. Las repercusiones de la crisis regional estadunidense en la politica exterior bacia México, Secretaría de Relaciones Exteriores, México, 1997.

-Hargous, Peter A. y la New Orleans Company, Remonstrance against the report and resolutions of the mexican Congress annulling the Tehuantepec grant ffor want of autbority in the government which conceded its extension] addressed to the go- vernment of the United States, by the american proprietors of the exclusive right of way across the isthmus of Tebuantepec [Gideon Print, Washington, 1852].

-[Larrainzar, Manuel], Análisis del dictamen de la comisión de negocios extranjeros del Senado de Estados Unidos sobre el negocio de Tebuantepec, [s. e., Washington], 1852.

-Larrainzar, Manuel, La cuestión de Tebuantepec. Contiene dos notas del enviado extraordinario y ministro plenipotenciario de la república mexicana en Washington, $y$ algunos artículos que sobre esta materia se han publicado, Juan F. Trow, Nueva York, 1852.

, Via de comunicación interoceánica por el istmo de Tebuantepec; escrito en que se da a conocer su importancia: cuándo se concibió esta idea; su bistoria basta nuestros dias; concesiones y reconocimientos que se ban becho para la apertura y sus resultados; lo que es en si el istmo; riqueza de sus producciones, $y$ facilidades $y$ ventajas que presenta para la ejecución del proyecto, y probabili. dades de su pronta realización, Ignacio Cumplido, México, 1877.

-"Message from the president of the United States, in answer to a resolution of the Senate calling for the correspondence between the governments of the United States and Mexico, respecting a right of way across the isthmus of Tehuantepec", Washington, 27 de julio de 1852,32 Congreso, 1a. sesión, Senate Executive Documents, núm. 97, serial 621 .

-Nelson, Anna Kasten, "Destiny and diplomacy, 1840-1865" en Gerald K. Haines y J. Samuel Walker, American foreign relations. A bistoriographical review, Greenwood Press, Westport, Connecticut, 1981, pp. 49-64.

-Olliff, Donathon C., Reforma Mexico and the United States: a search for alternatives to annexation. 1854-1861, University of Alabama Press, Alabama, 1981. 
-Pletcher, David M., The diplomacy of annexation. Texas, Oregon and the mexican war, The University of Missouri Press, Columbia, 1975.

-Ramírez, José Fernando, Memoria instructiva de los derechos y justas causas que tiene el gobierno de los Estados-Unidos Mexicanos para no reconocer ni la subsistencia del privilegio concedido a don José de Garay para abrir una vía de comunicación entre los oceános Atlántico y Pacifico por el istmo de Tebuantepec, ni la legitimidad de la cesión que aquél bizo del mismo privilegio a ciudadanos de los Estados-Unidos de la América del Norte, Tipografía de Vicente G. Torres, México, 1852.

Memorias, negociaciones $y$ documentos para servir a la bistoria de las diferencias que ban suscitado entre México y los Estados-Unidos, los tenedores del antiguo privilegio, concedido para la comunicación de los mares Atlántico y Pacifico, por el istmo de Tebuantepec, Imprenta de Ignacio Cumplido, México, 1853.

-"Report of the Select Committee on the Senate, in relation to the proceedings of the board of commissioners on the claims against Mexico", 33 Congreso, 1a. sesión, Senate Reports, 28 de marzo de 1854, núm. 182, microficha 708 .

-"Report: The Committee on Foreign Relations, to whom has been referred the message of the president of the United States of the 27 th july, 1852 , communicating the correspondence between the government of the United States and the republic of Mexico, respecting the right of way across the isthmus of Tehuantepec [...]", 32 Congreso, 1a. sesión, Senate Reports, núm. 355, serial 631 .
-"Resolution on right of way across the isthmus of Tehuantepec", Washington, 30 de agosto de $1852,32^{\circ}$ Congreso, 1a. sesión, Senate Miscellaneous Documents, núm. 111, serial 629.

-Rippy, J. Fred, "Diplomacy of the United States and Mexico regarding the isthmus of Tehuantepec, 1848-1860", Mississippi Valley Historical Review, marzo de 1920 , v. 6, núm. 4, pp. 503-531.

-Schoonover, Thomas David, Dollars over dominion. The triumph of liberalism in Mexican-United States Relations, 18611867, Louisiana State University Press, Baton Rouge, 1978.

-Shewmaker, Kenneth E. y Kenneth R. Stevens (comps.), The papers of Daniel Webster. Diplomatic papers, volume 2. 1850-1852, The University Press of New England, Hanover, New Hampshire, 1987.

-Suárez Argüello, Ana Rosa y Marcela Terrazas Basante (comps.), Política y negocios. Ensayos sobre la relación entre México y los Estados Unidos en el siglo $\mathrm{XXX}$, Universidad Nacional Autónoma de México/Instituto Mora, México, 1997.

-Suárez Argüello, Ana Rosa, “Expansión territorial o imperio comercial? El gobierno whig y la cuestión de Tehuantepec (18491853) en Ana Rosa Suârez Argüello (comp.), Pragmatismo $y$ principios. La relación conflictiva entre México y Estados Unidos, 1810-1942, Instituto Mora, México, 1998.

-Tornel, José María, Voto particular del señor senador D. José María Tornel, individuo de la comisión especial que entiende en los negocios relativos al istmo de Tebuantepec, sobre privilegio de abrir la via de comunicación, Imprenta de Vicente García Torres, México, 1852. 